\title{
Kelayakan Modul Pencemaran Lingkungan Berbasis Environmental Worldview dan Environmental Attitudes
}

\author{
Muhammad Syamsussabri ${ }^{1}$, Sueb $^{1}$, Suhadi $^{1}$ \\ ${ }^{1}$ Pendidikan Biologi-Universitas Negeri Malang
}

\section{INFO ARTIKEL}

\section{Riwayat Artikel:}

Diterima: 27-05-2019

Disetujui: 15-09-2019

Kata kunci:
feasibility analysis;
environmental pollution module;
environmental worldview;
environmental attitudes;
analisis kelayakan;
modul pencemaran lingkungan;
environmental worldview;
environmental attitudes

\section{Alamat Korespondensi:}

Muhammad Syamsussabri

Pendidikan Biologi

Universitas Negeri Malang

Jalan Semarang 5 Malang

E-mail: sueb.fmipa@um.ac.id

\section{ABSTRAK}

\begin{abstract}
This type of research was quantitative descriptive. This research is aimed at determining feasible of the module of environmental pollution based on environmental worldview and environmental attitudes consist of test for content validity by an expert lecturer in environmental science, module design validity by an expert lecturer in module design, practicality by a teacher at SMAN 1 Lembar, and legibility by 20 students at SMAN 1 Lembar. The method used was questionnaires and analyzed by percentage. The test result showed the module was very feasibly with had an average of $94.6 \%$ and concluded that the module feasible to used in learning.
\end{abstract}

\begin{abstract}
Abstrak: Jenis penelitian ini yaitu deskriptif kuantitatif. Penelitian ini bertujuan untuk menentukan kelayakan modul pencemaran lingkungan berbasis environmental worldview and environmental attitudes yang terdiri dari uji validitas isi oleh dosen ahli di bidang ilmu lingkungan, validitas desain modul oleh dosen ahli modul, kepraktisan oleh guru di SMAN 1 Lembar, dan keterbacaan oleh 20 siswa di SMAN 1 Lembar. Metode yang digunakan yaitu kuesioner dan dianalisis dengan persentase. Hasil tes menunjukkan modul sangat layak dengan rerata $94,6 \%$ dan disimpulkan bahwa modul layak digunakan dalam pembelajaran.
\end{abstract}

Pendidikan memiliki peran guna menciptakan sumber daya manusia yang berkualitas. Melalui pendidikan, diharapkan tercipta manusia berjiwa inovatif, yang dapat mengembangkan potensi diri dan berperan dalam pembangunan di berbagai aspek kehidupan (Badan Pusat Statistik (BPS), 2017). Pendidikan harus terus membuat inovasi yang lebih baik untuk menghadapi tantangan masa depan dan memenuhi kebutuhan masyarakat. Salah satu upaya yang bisa dilakukan untuk mewujudkan harapan tersebut adalah dengan menyediakan fasilitas yang sesuai dengan pengembangan ilmu pengetahuan dan teknologi (Padmapriya, 2015). Salah satu upaya yang bisa dilakukan guna meningkatkan kualitas pendidikan yaitu dengan mengembangkan bahan ajar yang sesuai dengan kurikulum dan kondisi peserta didik yang dibelajarkan (Barron \& Darling-Hammond, 2008; Depdiknas, 2006). Bahan ajar yang dikembangkan sesuai kebutuhan guru dan siswa serta dimanfaatkan secara benar akan menjadi salah satu faktor penting yang dapat meningkatkan mutu pembelajaran (Sadjati, 2012).

Bahan ajar yang baik tidak hanya dapat meningkatkan pemahaman konseptual, tetapi juga meningkatkan keterampilan seperti menganalisis, menafsirkan, merangkum, dan memecahkan masalah dengan solusi kreatif) (Barron \& Darling-Hammond, 2008). Bahan ajar dapat mengubah peran guru dan siswa dalam proses pembelajaran. Pada mulanya guru merupakan sumber satusatunya informasi di kelas dan siswa hanya sebagai penerima informasi. Dengan adanya bahan ajar maka guru tidak hanya menjadi sumber belajar satu-satunya di kelas, melainkan guru lebih diarahkan untuk berperan sebagai fasilitator siswa dalam proses pembelajaran. Sementara itu, dengan menggunakan bahan ajar yang dikembangkan sesuai kebutuhan siswa, maka siswa diarahkan untuk menjadi pembelajar yang aktif dengan mempelajari materi yang terdapat pada bahan ajar terlebih dahulu sebelum mengikuti pembelajaran di kelas. Salah satu bahan ajar yang dapat digunakan dalam pembelajaran ialah modul.

Modul ialah bahan ajar cetak yang disusun untuk dapat dipelajari oleh peserta didik secara mandiri. Modul disebut juga sebagai bahan ajar mandiri karena di dalamnya telah dilengkapi petunjuk untuk belajar sendiri yang artinya peserta didik dapat melakukan kegiatan belajar tanpa adanya pendidik secara langsung (Depdiknas, 2008). Modul ialah bahan ajar yang disusun sesuai dengan pokok bahasan, rancangan pembelajaran, dan disebarluaskan kepada peserta didik untuk digunakan dalam kegiatan pembelajaran (Kemenristekdikti, 2017). Penggunaan modul sangat penting dalam pembelajaran karena tidak terbatasi oleh waktu belajar sehingga dapat digunakan untuk pembelajaran secara aktif dan rinci dari materi yang dipelajari (Shah, Cox, \& Zdanowicz, 2013). 
Modul merupakan salah satu bahan ajar yang cocok dikembangkan dan digunakan sesuai dengan kondisi lingkungan peserta didik. Modul berbasis environmental worldview dan environmental attitudes pada materi pencemaran lingkungan telah dikembangkan dan sesuai dengan analisis kebutuhan guru dan siswa serta kondisi lingkungan sekitar siswa (Syamsussabri \& Sueb, 2018). Wawasan lingkungan ialah kumpulan asumsi dan keyakinan tentang bagaimana alam bekerja dan bagaimana manusia berhubungan dengan lingkungan, termasuk etika lingkungan, atau keyakinan tentang apa yang benar atau salah dengan cara kita memperlakukan lingkungan (Miller et al., 2009). Wawasan lingkungan juga diartikan sebagai cara pandang manusia terhadap lingkungannya (Sueb, 2015). Wawasan lingkungan ini dapat diukur menggunakan skala New Ecological Paradigm (NEP) dengan lima indikator, di antaranya (1) realitas batas pertumbuhan, (2) anti antroposentrisme, (3) kerusakan keseimbangan alam, (4) menolak eksemptionalisme, dan (5) krisis ekologis (Dunlap, Van Liere, Mertig, \& Jones, 2000).

Wawasan lingkungan sangat berhubungan erat dengan sikap lingkungan. Sikap lingkungan ialah tingkat kesadaran dan pengetahuan tentang lingkungan, dukungan dan upaya yang dilakukan terhadap masalah lingkungan dan/atau inisiatif untuk berkontribusi secara pribadi untuk menemukan solusi bagi lingkungan (Dunlap \& Michelson, 2002). Sikap lingkungan terbagi menjadi dua komponen utama yaitu lingkungan dan kepedulian. Komponen lingkungan mengacu pada masalah heterogenitas dan masalah lingkungan sementara komponen kepedulian menyangkut ekspresi kepedulian terhadap lingkungan atau respons seseorang terhadap lingkungan sekitar (Dunlap \& Michelson, 2002). Sikap lingkungan dapat diukur menggunakan Environmental Attitude Inventory (EAI) dengan 12 indikator di antaranya (1) kenikmatan alam, (2) dukungan kebijakan konservasi, (3) aktivitas gerakan lingkungan, (4) motivasi konservasi, (5) keyakinan terhadap sains dan teknologi, (6) ancaman lingkungan, (7) mengubah alam, (8) perilaku konservasi, (9) dominasi manusia atas alam, (10) pemanfaatan alam oleh manusia, (11) perhatian ekosentrik, dan (12) dukungan terhadap kebijakan pertumbuhan populasi (Milfont \& Duckitt, 2010).

Berkaitan dengan uji kelayakan modul, hal yang dicermati ialah apakah modul yang dikembangkan sudah sesuai dengan konsep pengetahuan dan tujuan pembelajaran yang ingin dicapai (BNSP, 2016; Depdiknas, 2008). Kelayakan modul diukur bila teah memenuhi kevalidan isi/materi, kevalidan desain bahan ajar yang dikembangkan, kepraktisan pembelajaran, dan keterbacaan (BNSP, 2016; Depdiknas, 2008; Kemenristekdikti, 2017). Validitas dan kepraktisan ini dapat diperoleh melalui penilaian para pakar di bidangnya (BNSP, 2016). Sementara keterbacaan selalu dihubungkan dengan bacaan dan pembaca. Aspek ini memastikan materi bahan bacaan, jenis bacaan, kesulitan bacaan, dan karakteristik penyajian bacaan. Selain itu, juga dipertimbangkan latar belakang pembaca dilihat dari faktor usia, pendidikan, aktivitas, kemampuan, dan minat baca. Oleh karena itu, keterbacaan dapat diartikan sesuai tidaknya suatu bacaan bagi pembaca tertentu dilihat dari segi tingkat kesukarannya (Tampubolon, 1990). Berdasarkan pernyataan di atas maka perlu dilakukan uji kelayakan modul yang terdiri uji validitas materi, uji validitas desain modul, uji kepraktisan modul, dan uji keterbacaan modul yang telah disusun bertujuan untuk mengetahui apakah modul yang dikembangkan telah layak untuk diimplementasikan pada jenjang SMA/MA.

\section{METODE}

Penelitian ini merupakan penelitian deskriptif kuantitatif yang bertujuan untuk menguji kelayakan bahan ajar modul pencemaran lingkungan berbasis environmental worldview (Dunlap et al., 2000) dan environmental attitudes. (Milfont \& Duckitt, 2010) Modul yang diuji kelayakan merupakan modul yang telah disusun menggunakan model pengembangan ADDIE. (Branch, 2009) Instrumen yang digunakan dalam penelitian ini yaitu lembar kuesioner yang terdiri dari lembar validasi materi (30 pernyataan), lembar validasi desain bahan ajar (35 pernyataan), lembar kepraktisan (21 pernyataan), dan lembar keterbacaan (19 pernyataan) yang telah disusun dan modifikasi sesuai konteks penelitian (BNSP, 2016; Depdiknas, 2008; Kemenristekdikti, 2017; Permendikbud, 2016). Penelitian ini dilaksanakan pada bulan Maret-April 2019. Adapun kualifikasi validator dan praktisi lapangan sebagaimana ditunjukkan pada tabel 1. Hasil persentase selanjutnya dikategorikan berdasarkan kriteria sebagaimana ditunjukkan pada tabel 2.

Tabel 1. Kualifikasi Validator dan Praktisi Lapangan

\begin{tabular}{lllll}
\hline No & \multicolumn{1}{c}{ Validator } & \multicolumn{1}{c}{ Nama } & \multicolumn{1}{c}{ Pengalaman } & \multicolumn{1}{c}{ Instansi } \\
\hline 1 & Ahli Materi & Drs. Khairuddin, M.Eng & $\begin{array}{l}\text { Mengajar Ilmu Lingkungan } \\
\text { selama 30 Tahun }\end{array}$ & $\begin{array}{l}\text { Dosen Pendidikan Biologi, FKIP, } \\
\text { Universitas Mataram }\end{array}$ \\
2 & Ahli Bahan Ajar & $\begin{array}{l}\text { Dr. Henry Praherdhiono, } \\
\text { S.Si., M.Pd }\end{array}$ & $\begin{array}{l}\text { Mengajar Media Pembelajaran } \\
\text { selama 14 Tahun }\end{array}$ & $\begin{array}{l}\text { Dosen Teknologi Pembelajaran, FIP, } \\
\text { Universitas Negeri Malang }\end{array}$ \\
3 & Praktisi Lapangan & Suhartini, S.Pd & $\begin{array}{l}\text { Mengajar Mata Pelajaran } \\
\text { Biologi selama 6 Tahun }\end{array}$ & Guru Biologi SMAN 1 Lembar \\
\hline
\end{tabular}


Untuk uji keterbacaan dilakukan pada siswa kelas XI MIPA sebanyak 20 orang. Setiap uji dianalisis dengan persentase untuk menentukan kriteria modul. Adapun rumus yang digunakan sebagai berikut.

$$
\text { Persentase }=\frac{\text { Jumlah Skor yang diperoleh }}{\text { Jumlah Skor Maksimal Ideal }} \times 100 \%
$$

Tabel 2. Kriteria Modul

\begin{tabular}{cclll}
\hline No & Persentase & $\begin{array}{c}\text { Tingkat Kevalidan, Kepraktisan, dan } \\
\text { Keterbacaan }\end{array}$ & Kriteria & Keterangan \\
\hline 1 & $0-54 \%$ & Tidak Valid/Praktis/Terbaca & Tidak Baik & Revisi \\
2 & $55-64 \%$ & Kurang Valid/Praktis/Terbaca & Kurang Baik & Revisi \\
3 & $65-79 \%$ & Cukup Valid/Praktis/Terbaca & Cukup Baik & Revisi \\
4 & $80-89 \%$ & Valid/Praktis/Terbaca & Baik & Revisi \\
5 & $90-100 \%$ & Sangat Valid/Praktis/Terbaca & Sangat Baik & Tidak Revisi \\
\hline
\end{tabular}

Sumber: Modifikasi (Purwanto, 2009)

\section{HASIL}

Berikut tampak halaman modul pencemaran lingkungan berbasis environmental worldview dan environmental attitudes yang telah dikembangkan dengan model pengembangan ADDIE.

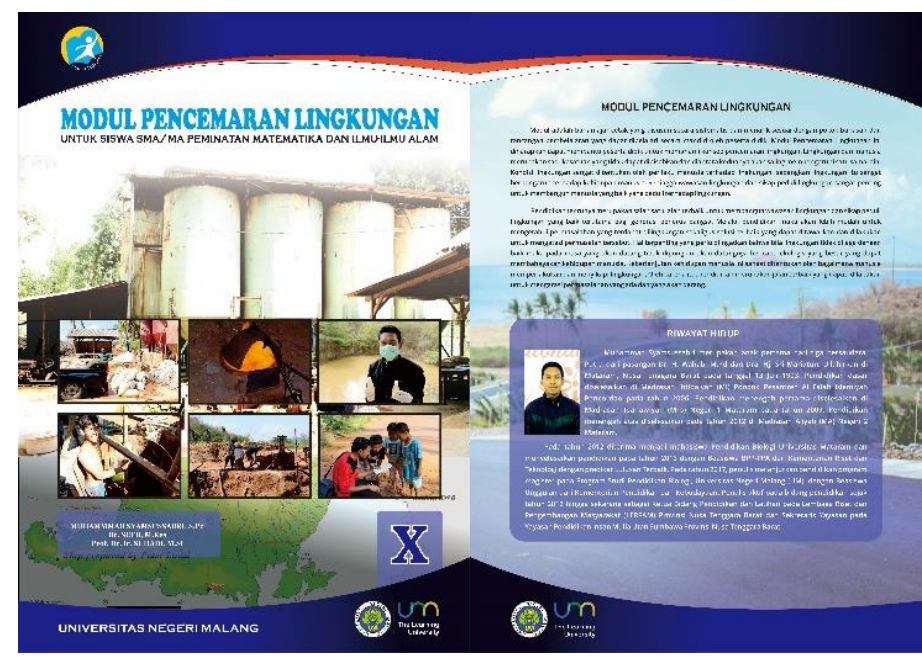

\section{Gambar 1. Halaman Depan Modul Pencemaran Lingkungan Berbasis Environmental Worldview dan Environmental Attitudes}

Kelayakan modul pencemaran lingkungan diukur berdasarkan hasil uji validitas materi, validitas desain bahan ajar, kepraktisan, dan keterbacaan modul pencemaran lingkungan dengan hasil sebagaimana ditunjukkan pada tabel 3.

Tabel 3. Hasil Uji Validitas Materi Modul Pencemaran Lingkungan

\begin{tabular}{clcccc}
\hline No & \multicolumn{1}{c}{ Indikator } & Jumlah Penyataan & Rerata & Persentase (\%) & Kategori \\
\hline 1 & Organisasi Materi & 9 & 4,7 & 93,3 & Sangat Valid \\
2 & Cakupan Materi & 7 & 4,9 & 97,1 & Sangat Valid \\
3 & Akurasi Materi & 6 & 4,3 & 86,7 & Valid \\
4 & Kemutahiran Materi & 4 & 5 & 100 & Sangat Valid \\
5 & Mengandung Wawasan Produktivitas & 2 & 5 & 100 & Sangat Valid \\
6 & Memacu Keingintahuan (Curiosity) & 1 & 5 & 100 & Sangat Valid \\
7 & Mengembangkan Nilai Keberagaman (Sense of Diversity) & 1 & 5 & 100 & Sangat Valid \\
8 & Mengembangkan Keterampilan Hidup (Life Skills) & 1 & 5 & 100 & Sangat Valid \\
\hline \multicolumn{2}{r}{ Rerata Persentase Validitas } & & 97,1 & Sangat Valid \\
\hline
\end{tabular}


Tabel 4. Hasil Uji Validitas Desain Bahan Ajar Modul Pencemaran Lingkungan

\begin{tabular}{clcccc}
\hline No & \multicolumn{1}{c}{ Indikator } & Jumlah Penyataan & Rerata & Persentase (\%) & Kategori \\
\hline 1 & Ukuran Modul & 2 & 5 & 100 & Sangat Valid \\
2 & Bagian Halaman & 5 & 5 & 100 & Sangat Valid \\
& Sampul Modul & 4 & 5 & 100 & Sangat Valid \\
& & & & & \\
3 & Kegrafisan Modul & 8 & 5 & 100 & Sangat Valid \\
4 & Bagian Isi Modul & 9 & 4,9 & 97,8 & Sangat Valid \\
& Bagian Awal & 7 & 4,8 & 97,1 & Sangat Valid \\
& Bagian Inti & & & \\
\hline & Bagian Penutup & & & \\
\hline & Rerata Persentase Validitas & & \\
\hline
\end{tabular}

Tabel 5. Hasil Uji Kepraktisan Modul Pencemaran Lingkungan

\begin{tabular}{|c|c|c|c|c|c|}
\hline No & Indikator & Jumlah Penyataan & Rerata & Persentase (\%) & Kategori \\
\hline 1 & Teknik Penyajian & 8 & 4,8 & 95 & Sangat Praktis \\
\hline 2 & Pendukung Penyajian Materi & 4 & 4,5 & 90 & Sangat Praktis \\
\hline 3 & Penyajian Pembelajaran & 9 & 4,6 & 91,1 & Sangat Praktis \\
\hline \multicolumn{4}{|c|}{ Rerata Persentase Kepraktisan } & 92 & Sangat Praktis \\
\hline
\end{tabular}

Tabel 6. Hasil Uji Keterbacaan Modul Pencemaran Lingkungan



Gambar 2. Persentase Uji Kelayakan Modul Pencemaran Lingkungan

PEMBAHASAN

Berdasarkan analisis kebutuhan yang dilakukan di SMAN 1 Lembar, siswa membutuhkan bahan ajar berupa modul sebagai alternatif yang dapat menunjang proses pembelajaran. Bahan ajar ini sangat cocok dikembangkan terutama pada materi pencemaran lingkungan bila dilihat dari kondisi siswa yang kesehariannya berinteraksi dengan limbah hasil pengolahan emas yang dilakukan oleh masyarakat sekitar (Syamsussabri \& Sueb, 2018). Modul ini dikembangkan berbasis environmental worldview (Dunlap et al., 2000) dan environmental attitudes (Milfont \& Duckitt, 2010) dengan harapan dapat meningkatkan wawasan lingkungan (Dunlap \& Michelson, 2002; Sueb, 2015) dan sikap lingkungan (Milfont \& Duckitt, 2010). Kurangnya pengetahuan terhadap lingkungan dapat menyebabkan rendahnya sikap lingkungan yang dimiliki oleh seseorang (Mifsud, 2011). Pengetahuan tentang lingkungan merupakan aspek yang sangat penting. Pengetahuan tentang lingkungan akan memengaruhi sikap dan perilaku seseorang terhadap lingkungannya. Pengetahuan tentang perilaku yang ramah lingkungan merupakan komponen utama faktor internal yang dapat menyebabkan perubahan sikap seseorang agar lebih ramah terhadap lingkungan (Badan Pusat Statistik (BPS), 2015). Sikap lingkungan merupakan hal yang perlu untuk dipahami. Alasan paling intuitif untuk memahami sikap lingkungan dikarenakan dapat menunjukkan tingkah laku terbaik bagi lingkungan (Gifford \& Sussman, 2012) . 
Modul merupakan salah satu bahan ajar yang dapat menjadi alternatif yang dapat digunakan siswa untuk memahami materi pelajaran secara mandiri (Depdiknas, 2008). Modul pencemaran lingkungan adalah bahan ajar cetak yang disusun secara sistematis dan menarik berdasarkan hasil penelitian pencemaran $\mathrm{Hg}$ dan $\mathrm{CN}$ di pertambangan emas rakyat Sekotong sesuai dengan pokok bahasan dan rancangan pembelajaran yang dapat dipelajari secara mandiri oleh peserta didik. Belajar menggunakan modul juga dapat memotivasi peserta didik dan dapat meningkatkan kemampuan berpikir. Modul yang dirancang dengan menghadirkan contoh nyata sesuai dengan kehidupan sehari-hari juga dapat mengembangkan keaksaraan peserta didik dan penguasaan konsep baru (Awang \& Zakaria, 2012). Suatu modul dapat dikatakan layak digunakan oleh siswa apabila telah memenuhi syarat kelayakan yang terdiri dari kelayakan isi/materi, kelayakan desain bahan ajar, kelayakan kepraktisan dalam pembelajaran, dan dapat terbaca oleh siswa dengan baik (BNSP, 2016; Depdiknas, 2008; Kemenristekdikti, 2017; Permendikbud, 2016).

Uji validitas materi bertujuan untuk mengetahui kevalidan dan kesesuaian isi/materi modul yang disusun dengan kompetensi dasar yang akan dicapai oleh siswa. Lembar validasi materi modul ini terdiri dari beberapa indikator antara lain: (1) organisasi materi, (2) cakupan materi, (3) akurasi materi, (4) kemutahiran materi, (5) mengandung wawasan produktivitas, (6) memacu keingintahuan (curiosity), (7) mengembangkan nilai keberagaman (sense of diversity), dan (8) mengembangkan keterampilan hidup (life skills) (Kemenristekdikti, 2017). Secara keseluruhan, uji validitas isi/materi modul memiliki persentase 97,1\% dengan kategori sangat valid. Secara isi/materi modul pencemaran lingkungan sangat sesuai dengan konteks pembelajaran yang di pelajari oleh siswa. Modul ini sudah sangat baik dan dapat digunakan tanpa melakukan revisi. Terdapat masukan dari validator materi terkait ukuran font pada keterangan gambar yang perlu diperbesar agar lebih mudah terbaca.

Uji validitas bahan ajar modul bertujuan untuk mengetahui kevalidan dan kesesuaian desain modul yang digunakan untuk siswa SMA/MA. Lembar validasi bahan ajar modul ini terdiri dari beberapa indikator, antara lain (1) ukuran modul, (2) bagian halaman sampul modul, (3) kegrafisan modul, dan (4) bagian isi modul yang terdiri dari bagian awal, bagian inti, dan bagian penutup) (Kemenristekdikti, 2017). Secara keseluruhan uji bahan ajar modul memiliki persentase 99,2\% dengan kategori sangat valid. Hasil ini menunjukkan bahwa desain bahan ajar modul pencemaran lingkungan sudah sangat baik dan bisa digunakan untuk pembelajaran siswa SMA/MA tanpa melakukan revisi. Salah satu komponen modul adalah kegiatan pembelajaran. Modul yang baik tidak hanya berisi kumpulan materi, tetapi ada juga kegiatan pembelajaran yang mengakomodasi proses aktif. Kegiatan pembelajaran harus kontekstual dengan lingkungan siswa (Widodo, Maria, \& Fitriani, 2017).

Uji kepraktisan modul bertujuan untuk mengetahui kepraktisan modul yang digunakan dalam kegiatan pembelajaran pada siswa SMA/MA. Lembar kepraktisan modul ini terdiri dari tiga indikator, yaitu (1) teknik penyajian, (2) pendukung penyajian materi, dan (3) penyajian pembelajaran (Kemenristekdikti, 2017). Kepraktisan ini disesuaikan dengan metode dan model pembelajaran yang digunakan dalam proses pembelajaran. Kegiatan pembelajaran yang disusun dalam modul harus dapat dipraktikkan oleh peserta didik secara mandiri dan dapat mengembangkan proses aktif mereka (Bradley \& Brown, 2006). Kegiatan pembelajaran yang mengembangkan proses aktif dapat dipersiapkan dengan memasukkan unsur-unsur pendekatan ilmiah dari kurikulum 2013. Penyusunan kegiatan pembelajaran yang sesuai dengan pendekatan ilmiah, dapat diterapkan dengan mudah karena lebih koheren dan logis (Taufiq, Dewi, \& Widiyatmoko, 2014). Pada modul ini digunakan model Problem Based Learning (PBL) (Seng, 2003). Penggunaan model PBL ini diharapkan dapat mengorganisasikan pembelajaran agar lebih baik dan terarah. Secara keseluruhan, uji kepraktisan memiliki persentase 92\% dengan kategori sangat praktis. Hasil ini menunjukkan bahwa modul ini sangat baik dan bisa digunakan tanpa dilakukan revisi.

Uji keterbacaan modul bertujuan untuk mengetahui tingkat keterbacaan siswa terhadap modul baik itu dari segi indikator (1) tampilan, (2) penyajian, (3) bahasa, dan (4) manfaat (Kemenristekdikti, 2017). Keterbacaan modul ini sangat penting diukur karena untuk mengukur kesesuaian kemampuan siswa dalam menggunakan modul sebagai salah satu alternatif bahan ajar. Tentunya semakin terbaca modul yang digunakan maka semakin mudah siswa dalam mempelajari materi yang terdapat pada modul. Secara keseluruhan modul pencemaran lingkungan memiliki persentase $90 \%$ dengan kategori sangat terbaca. Hasil ini menunjukkan bahwa modul ini dikategorikan sangat baik dan dapat digunakan dalam pembelajaran tanpa melakukan revisi.

Berdasarkan persentase yang didapatkan dari validasi materi, desain bahan ajar, kepraktisan, dan keterbacaan maka dapat diketahui persentase kelayakan modul pencemaran lingkungan memiliki rerata persentase sebesar 94,6\% dengan kategori sangat layak. Hasil ini menunjukkan bahwa modul yang dikembangkan sudah bisa diimplementasikan sebagai salah satu bahan ajar pada materi pencemaran lingkungan pada siswa SMA/MA.

\section{SIMPULAN}

Berdasarkan hasil analisis menunjukkan bahwa modul pencemaran lingkungan sangat layak untuk diimplementasikan pada materi pencemaran lingkungan untuk siswa SMA/MA dengan persentase rerata sebesar 94,6\%. Perlu dilakukan pengembangan bahan ajar lainnya yang berbasis environmental worldview dan environmental attitude dengan konteks materi di sekitar peserta didik dengan harapan dapat meningkatkan pengetahuan dan kepedulian lingkungan. 


\section{DAFTAR RUJUKAN}

Awang, T. S., \& Zakaria, E. (2012). Module for Learning Integral Calculus with Maple: Lecturers' Views. Turkish Online Journal of Educational Technology-TOJET, 11(3), 234-245.

Badan Pusat Statistik (BPS). (2015). Indikator Perilaku Peduli Lingkungan Hidup 2014. Jakarta.

Badan Pusat Statistik (BPS). (2017). Potret Pendidikan Indonesia. Jakarta.

Barron, B., \& Darling-Hammond, L. (2008). Teaching for Meaningful Learning: A Review of Research on Inquiry-Based and Cooperative Learning. Powerful Learning: What We Know about Teaching for Understanding, 11-70.

BNSP. (2016). Peraturan Menteri Pendidikan dan Kebudayaan Nomor 22 Tahun 2016 tentang Standar Proses Pendidikan Dasar dan Menengah. Jakarta: BNSP.

Bradley, B. W., \& Brown, R. T. (2006). Assesing Process Skills. San Francisco: Exploratorium.

Branch, R. M. (2009). Instructional Design: The ADDIE Approach (Vol. 722). Springer Science \& Business Media.

Depdiknas. (2006). Pedoman Memilih dan Menyusun Bahan Ajar (Departemen Pendidikan Nasional). Jakarta.

Depdiknas. (2008). Penulisan Modul (Departemen Pendidikan Nasional). Jakarta.

Dunlap, R. E., \& Michelson, W. (2002). Handbook of Environmental Sociology. Greenwood Publishing Group.

Dunlap, R. E., Van Liere, K. D., Mertig, A. G., \& Jones, R. E. (2000). New Trends in Measuring Environmental Attitudes: Measuring Endorsement of the New Ecological Paradigm: A Revised NEP scale. Journal of Social Issues, 56(3), 425442.

Gifford, R., \& Sussman, R. (2012). Environmental Attitudes. The Oxford Handbook of Environmental and Conservation Psychology, 65-80.

Kemenristekdikti. (2017). Panduan Penyusunan Perangkat Pembelajaran \& Bahan Ajar. Jakarta.

Mifsud, M. C. (2011). An Investigation on the Environmental Knowledge, Attitudes and Behavior of Maltese Youth. Online Submission.

Milfont, T. L., \& Duckitt, J. (2010). The Environmental Attitudes Inventory: A Valid and Reliable Measure to Assess the Structure of Environmental Attitudes. Journal of Environmental Psychology, 30(1), 80-94. https://doi.org/https://doi.org/10.1016/j.jenvp.2009.09.001

Miller, G. T., Spoolman, S. E., Malatesta, K., Yip, L., Marinkovich, A., Hugel, R., \& Ciemma, R. (2009). Living in the Environment: Concepts, Connections, and Solutions, 16e. International Student Edition. Belmont: Brooks/Cole, Cengage Learning.

Padmapriya, P. V. (2015). Effectiveness of Self Learning Modules on Achievement in Biology among Secondary School Students. International Journal of Education and Psychological Research, 4(2), 44-46.

Permendikbud. (2016). Peraturan Menteri Pendidikan dan Kebudayaan Republik Indonesia Nomor 8 Tahun 2016 tentang Buku yang digunakan oleh Satuan Pendidikan.

Seng, T. O. (2003). Problem Based Learning Innovation: Using Problem to Power Learning in $21^{\text {th }}$ Century. Singapore: Thomson Learning.

Shah, S., Cox, A. G., \& Zdanowicz, M. M. (2013). Student Perceptions of the Use of Pre-Recorded Lecture Modules and Class Exercises in a Molecular Biology Course. Currents in Pharmacy Teaching and Learning, 5(6), 651-658.

Sueb, S. (2015). Analisis Environmental Worldview Mahasiswa Biologi FMIPA Universitas Negeri Malang. Prosiding Seminar Nasional Biologi/IPA dan Pembelajarannya, 335-342.

Syamsussabri, M., \& Sueb, S. (2018). Need Analysis of Materials and Media Biology Teaching for High School Students Around the Location of People Gold Mining. International Conference on Mathematics and Science Education (ICoMSE), 175-180.

Tampubolon, D. P. (1990). Kemampuan Membaca: Teknik Membaca Efektif dan Efisien. Bandung: Penerbit Angkasa.

Taufiq, M., Dewi, N. R., \& Widiyatmoko, A. (2014). Pengembangan Media Pembelajaran IPA Terpadu Berkarakter Peduli Lingkungan Tema "Konservasi" Berpendekatan Science-Edutainment. Jurnal Pendidikan IPA Indonesia, 3(2).

Widodo, A., Maria, R. A., \& Fitriani, A. (2017). Constructivist Learning Environment During Virtual and Real Laboratory Activities. Biosaintifika: Journal of Biology \& Biology Education, 9(1), 11-18. 